\title{
Relevance of Feyerabend's Scientific Anarchism to Scientific Advancement in Nigeria
}

\author{
Eugene Anowai*, Christian Okafor \\ Department of Philosophy, Chukwuemeka Odumegwu Ojukwu University, Igbariam, Nigeria \\ Email: *chukwueloka@yahoo.co.uk, okafortobechukwu1@gmail.com
}

How to cite this paper: Anowai, E., \& Okafor, C. (2018). Relevance of Feyerabend's Scientific Anarchism to Scientific Advancement in Nigeria. Open Journal of Philosophy, 8, 506-521. https://doi.org/10.4236/ojpp.2018.85035

Received: August 8, 2018

Accepted: November 10, 2018

Published: November 13, 2018

Copyright $\odot 2018$ by authors and Scientific Research Publishing Inc. This work is licensed under the Creative Commons Attribution International License (CC BY 4.0).

http://creativecommons.org/licenses/by/4.0/

\section{c) (i) Open Access}

\begin{abstract}
Against the western philosophy of globalization's belief in only one system or a "rational" standard of justification, Paul Feyerabend defends methodological anarchism, which holds that there are alternative systems within which coherence can still be established. Feyerabend, in his objection and rejection of universal standard on method, holds that there are many systems and (even within science itself), each with its own standards of justification and as such, it is not possible to choose between them "rationally", for they are incommensurable. So, in the place of the "rationality" of universal scientific and technological method, he talks of methodological plurality, or what he terms "Epistemological (Scientific) Anarchism". On this ground, development, whether scientifically or technologically, must not be considered by some universal criteria, but should be sought on the bases of cultural heritage and geographical differences of each society. Thus, this essay is a clarion call on Nigeria (and Africa at large) to channel her scientific and technological developmental efforts to suit her socio-political demands as well as the particular cultural needs of her people.
\end{abstract}

\section{Keywords}

Globalisation, Anarchism, Pluralism, Cultural Heritage, Development, Science \& Technology

\section{Introduction}

Today, there is little doubt that general attention in philosophy of science has been redirected to the details of science and, in particular, of its historical development (and procedures) by post-positivist philosophers like Hanson, Feyerabend, Kuhn, Lakatos, and others. These procedures for attaining scientific 
knowledge are known as scientific methods. These methods include formulating theories and testing them against observations and experiments. Ancient and medieval thinkers called any systematic body of knowledge a "science", and their methods were aimed at knowledge in general. According to the most common model for scientific knowledge formulated by Aristotle, induction yields universal propositions from which all knowledge in a field can be deduced. This model was refined by medieval and early modern thinkers, and further developed in the nineteenth century by Whewell and Mill.

The methods of careful observation and experiment have been in use from antiquity, but became more widespread after the seventeenth century. Developments in instrument making, in mathematics and statistics, in terminology and in communication technology have all altered the methods and results of science. It is against this background of the alteration of the methods and the results of science, that Feyerabend became famous for advocating "scientific anarchism"-the position that there is no such thing as scientific method, so that in advancing scientific research "anything goes". He writes:

It is clear then that the idea of a fixed method, or of a fixed theory of rationality, rests on too naïve a view of man and his social surroundings... It will become clear that there is only one principle that can be defended under all circumstances and in all stages of human development. It is the principle: anything goes (Feyerabend, 1993).

He also argues that the scientific outlook is itself just one approach to dealing with the world, an approach that is not self-evidently superior in all respects to other approaches. Thus, he writes: "Science is neither a single tradition nor the best tradition there is, except for people who have become accustomed to its presence, its benefits and its disadvantages" (Feyerabend, 1993).

Feyerabend believes that other forms of life which science considers as erroneous and unfitting must not be jettisoned because the history of science itself is full of inconsistencies and errors. Therefore, the upper hand privileges given to science in the society are unwarranted and unmerited by science. For him, various forms of knowledge like myths, magic, and the like which are considered irrational, not only contain some truth which cannot be discovered by science, but they also are not even more irrational than science. For this, he writes: "Science is only one of the many instruments people invented to cope with their surroundings. It is not the only one, it is not infallible" (Feyerabend, 1993).

Bringing this Feyerabend's philosophy of science home to the socio-political context of our country, Nigeria, it could be deduced that the present institutionalised criteria of rationality and standard of development as promoted by the capitalist western institutions are fallacious and even fraudulent. Thus, Kanu never minced words when he posited that the failure of the western prescriptions in Africa (Nigeria in particular), renders their capitalist rationality as "conventional foolishness" (Kanu, 2010). 


\section{Exposé of Feyerabend's Scientific Anarchism}

\subsection{Feyerabend's Analysis of the History of Science}

It is a very obvious fact that Feyerabend's essay on scientific anarchism is so much based on his conception and analysis of the history of science. Little wonder, he introduces the seminal work with the following passage from Lenin: "History, generally, and the history of revolution in particular, is always richer in content, more varied, more many-sided, more lively and subtle than even the best historian and the best methodologist can imagine" (Lenin, 1967). He then follows it suit with another from Butterfield, thus: "History is full of accidents and conjectures and curious juxtaposition of events" (Butterfield, 1965).

This is because the history of science, after all, does not just consist of facts and conclusions drawn from facts. It also contains ideas, interpretations of facts, problems created by conflicting interpretations, mistakes and so on. Thus, Feyerabend (1993) believes that on closer analysis, we even find that science knows no "bare facts" at all but that the "facts" that enter our knowledge are already viewed in a certain way and are, therefore, essentially ideational. This being the case, the history of science will be as complex, chaotic, full of mistakes, and entertaining as the ideas it contains, and these ideas in turn will be as complex, chaotic, full of mistakes, and entertaining as are the minds of those who invented them.

Indeed, one of the most striking features of recent discussions in the history and philosophy of science is the realization that events, and developments, such as the invention of atomism in antiquity, the Copernican Revolution, the rise of modern atomism (kinetic theory, dispersion theory, stereochemistry, quantum theory), the gradual emergence of the wave theory of light, could be all, arguably, seen to have occurred only because some thinkers either decided not to be bound by certain "obvious" methodological rules, or because they "unwittingly" broke them. Thus, Feyerabend posits that:

The idea of a method that contains firm, unchanging, and absolutely binding principles for conducting the business of science meets considerable difficulty when confronted with the results of historical research. We find, then, that there is not a single rule, however plausible, and however firmly grounded in epistemology, that is not violated at some time or other. It becomes evident that such violations are not accidental events, they are not results of insufficient knowledge or of inattention which might have been avoided. On the contrary, we see that they are necessary for progress (Feyerabend, 1993).

Many of the conflicts and contradictions which occur in science are due to this heterogeneity of the material, to the "unevenness" of the historical development, as Karl Marx (1918) would say, and they have no immediate theoretical significance. 


\subsection{Need for a New World-View}

In corroboration of Feyerabend's stance, Francis Bacon (1952) writes that what is needed for a test of Copernicus is an entirely new world-view containing a new view of man and of his capacities of knowing. This is because Bacon realized that scientific change involves a reformation not only of a few ideas, but of an entire world-view and, perhaps, of the very nature of humans "for the senses are weak and erring".

It is obvious that such a new world-view will take a long time appearing, and that we may never succeed to formulate it in its entirety. This need to wait, and to ignore large masses of critical observations and measurements, is hardly ever discussed in our methodologies. Disregarding the possibility that a new physics or a new astronomy might have to be judged by a new theory of knowledge and might require entirely new tests, empirically inclined scientists at once confront it with the status quo and announce triumphantly that "it is not in agreement with facts and received principles". They are of course right, and even trivially so, but not in the sense intended by them. For at any early stage of development, the contradiction only indicates that the old and the new are different and out of phase. It does not show which view is the better one (Feyerabend, 1993).

Sequel to the above fact, therefore, Feyerabend (1993) confronts us with the question: "how shall we proceed in order to bring about such a fair comparison?" To this question, he also gives us the response. According to him, first, "we must retain the new cosmology until it has been supplemented by the necessary auxiliary sciences. We must retain it in the face of plain and unambiguous refuting facts" (Feyerabend, 1993).

Thus, the new view is arbitrarily separated from data that supplemented its predecessor and is made more "metaphysical": a new period in the history of science commences with a backward movement that returns us to an earlier stage when theories were more vague and had smaller empirical content. This backward movement is not just an accident; it has a definite function. It is essential if we want to overtake the status quo, for it gives us the time and the freedom that are needed for developing the main view in detail, and for finding the necessary auxiliary sciences.

The world-view that happens to be at the center of attention and whose popular adoption causes us to carry out the backward step just described above differs from other "yet-to-be-adopted" views in one respect only: it has features which at the time in question seem so attractive to some people. But then, there is hardly any idea that is totally without merit and no idea is, therefore, completely without (abstract or empirical) support. Now, if partial support and partial plausibility suffice to start a new trend-just as Feyerabend suggests-if starting a new trend means taking a step back from the evidence; if any idea can become plausible and can receive partial support, then the step back is in fact "a step forward, and away from the tyranny of tightly-knit, highly corroborated, and gracelessly presented theoretical systems" (Feyerabend, 1993). 


\subsection{Counterinduction}

Analyzing Feyerabend's principle of scientific anarchism in concrete detail, we find ourselves with a principle he terms: "Counterinduction." This is a form of "counter rule" which proceeds in manners against the more familiar rules of the scientific enterprise. The counter rule advises us to introduce and elaborate hypotheses which are inconsistent with well-establish theories and/or well established facts-it advises us to proceed "counterinductively."

This counterinductive procedure gives rise to the following questions: Is counterinduction more reasonable than induction? Are there circumstances favouring its use? What are the arguments for it? What are the arguments against it? Is, perhaps, induction always preferable to counterinduction? And so forth. Feyerabend (1993) responds to these questions above in two steps: First, it emerges that the evidence that might refute a theory can often be unearthed only with the help of an incompatible alternative. He sees the advice (which goes back to Newton and which is still very popular today) to use alternatives only when refutations have already discredited the orthodox theory as putting the cart before the horse. Also, he believes that some of the most important formal properties of a theory are found by contrast, and not by analysis. A scientist who wishes to maximize the empirical content of the views he holds and who wants to understand them as clearly as he possibly can, must therefore introduce other views; that is, according to Feyerabend (1993), he must adopt a pluralistic methodology. He must compare ideas with other ideas rather than discard the views that have failed in the content.

The second step, according to Feyerabend (1993), which favours hypotheses inconsistent with observations, facts and experimental results, needs no special defense, for "there is not a single interesting theory that agrees with all the known facts in its domain." The question is, therefore, not whether counter inductive theories should be admitted into science; the question is, rather, whether the existing discrepancies between theory and facts should be increased, or diminished, or what else should be done to them.

To answer the above question, he offers us a good instance: the two statements-"the table is known", and "the table seems to be known"-indicate that there are occasions when our senses are capable of seeing the world "as it really is" and other times when they could be doubtful or even, worst still, deceived. Now, he tells us that usually, we are not even aware of them but only recognize their effects only when we meet with an entirely contrasting world-view. Thus, Feyerabend (1993) posits:

The material which the scientist has at his disposal, his most sublime theories and his most sophisticated techniques included, is structured in exactly the same way... (As a result, a theory may clash with the evidence not because the evidence is not correct, but because the evidence is contaminated). 
However, he goes further to elucidate that he has never merely intended to substitute the induction method (championed by Francis Bacon) with the counterinduction procedure as some people might even try to accuse him of. Rather, he mainly intends to convince his reader that all methodologies, even the most obvious ones, have their limits. Feyerabend (1993) sees an anarchist as "an undercover agent who plays the game of Reason in order to undercut the authority of Reason (Truth, Honesty, Justice and so on)."

\section{Galileo's Counterinductive Instance (The Copernican Revolution)}

In analyzing the transition from belief in Ptolemy to the belief in Copernicus in greater detail, Feyerabend (1993) pays greater concern to the role played by Galileo who first analyzed the Tower Argument of the Aristotelians with which they refuted the Copernican heliocentricism. According to this argument, the fact that a stone dropped from a tower falls straight down at the root of the tower proves that the earth is at rest; otherwise, the stone would fall farther away from the tower. This argument appeals more to our direct experience. Hence, Feyerabend calls such: natural interpretation. But this natural interpretation of this falling stone from a tower is erratic.

Thus, for Galileo to prove right the Copernican view, he had to replace this natural interpretation with a different one, which rather asserts the motion of the Earth. He was able to do this because he found out that, contrary to what others held, "it was the natural interpretation of the phenomenon, not the phenomenon [itself] that contradicted the Copernican view" (Munevar, 2000). $\mathrm{He}$ further asserted that commonly shared motion is indistinguishable; as such, a stone falling from a tower is seen to fall straight down at the root of the tower because the observers, the tower and the stone all share the common motion of the moving earth. But the new interpretation seemed unconvincing enough because empirical arguments are often more appealing, after all. Thus, according to Feyerabend, Galileo introduced propaganda (psychological and sophist's tricks) in his endeavour to convince his audience. Galileo reminded them that various situations point to the non-operative character of all motions such as events in a boat, in a smoothly moving carriage and in another system that contains an observer and permits him to perform simple operations.

On the other hand, the telescope's invention itself had its own shortcoming, too. Early telescopes were notoriously inaccurate and there was no principled manner in which to go about rectifying their problems: the optical theories existing at the time were not sufficient as a theoretical foundation for building the telescope. This meant that early observations with the telescope were often very wrong consisting greatly of illusions, distortions, and other problems. This situation also meant that early observations made with the telescope were equivocal, debatable, and sometimes contradicted by naked eye observations.

The only theory that could save the Galilean telescopic inadequacies was developed by Kepler-his theory of vision. But this theory itself is refuted by sim- 
ple experiment. ${ }^{1}$ Hence, Galileo's only reaction was to raise the telescope to a subtle "superior" and "better" sense. He did this because he so much supported Copernicanism and made effort to prove its veracity. So, though his telescopic results contradicted older world-view, they however supported the Copernican predictions. Obviously, Galileo, thus supported a refuted theory with another refuted one. Feyerabend (1993) states: "it is this rather peculiar situation, this harmony between two interesting but refuted ideas, which Galileo exploits in order to prevent the elimination of either."

\subsection{Proliferation of Theories against Consistency Condition}

Feyerabend believes that a scientist who is interested in maximal empirical content, and who wants to understand as many aspects of his theory as possible, would have to adopt a pluralistic methodology by comparing theories with other theories rather than with "experience", "data", or "facts", and he would also try to improve, rather than discard, the views that appear unpopular at the moment with the people. Hence, in the bid to advance the applicability of his counterinduction, he develops what he terms "theory proliferation", as against "consistency condition." While the former urges us to introduce hypotheses which are inconsistent (not correspondent) with well-established theories, the latter demands that new hypotheses must be consistent with such theories. On the matter, he writes:

Knowledge so conceived is not a series of self-consistent theories that converges towards an ideal view; it is not a gradual approach to the truth. It is rather an ever increasing ocean of mutually incompatible alternatives, each single theory, each fairy-tale, each myth that is part of the collection forcing the others into greater articulation and all of them contributing, via this process of competition, to the development of our consciousness (Feyerabend, 1993).

The above quotation indicates that the principle of proliferation not only recommends invention of new alternatives (ad hoc hypotheses), it also prevents the elimination of older ones which have been refuted. The reason is that such theories contribute to the content of their victorious rivals. This agrees with Lakatos' observation of 1971 that alternatives are not merely catalysts, which can later be removed in the rational reconstruction (Feyerabend, 1993).

\footnotetext{
${ }^{1}$ Modern theories of vision started with Johannes Kepler who in Ad Vitellionem Paralipomena (1604) first correctly described the formation of the retinal image in the eye. A few years later, Christoph Scheiner (1619) observed the retinal image by scraping away the sclera of the eye of an Ox which was placed in a hole in a shutter (reported by Descartes, 1637). However there was a problem-the retinal image was upside down. Why do we not see the world upside down? The answer to this problem is that the retinal image is not observed. If there existed a small man in the brain (a homunculus) looking at the retinal image then we would still need to explain how he sees the world and so on to an infinite regress. Kepler's theory of the retinal is pivotal. Old problems are not solved but they are explained away and new problems arise which still set the agenda today. Since the retinal image is two dimensional, how do we see a three dimensional world? How do we work out the real size of objects from their retinal size? How do we recognize an object is the same from different views? How can we see features that are not present in the retinal image?
} 
All the foregoing arguments lead Feyerabend to assert that the consistency condition which demands that new hypotheses agree with accepted theories is unreasonable because it often merely preserves the older theory, and not the better theory. He writes:

Hypotheses contradicting well-confirmed theories give us evidence that cannot be obtained in any other way. Proliferation of theories is beneficial for science, while uniformity impairs its critical power. Uniformity also endangers the free development of the individual (Feyerabend, 1993).

Feyerabend even further attacks the so-called consistency condition from the historical point of view. He cites instances like Newton's mechanics which was inconsistent with Galileo's law of free fall and with Kepler's laws; statistical thermodynamics which was inconsistent with the second law of the phenomenology theory; wave optics which was inconsistent with geometrical optics; and so forth. In all the above instances, the latter succeeded the former as a better theory by being first of all inconsistent with its preceding theories or facts.

More still, he criticizes this consistency condition based on demands of empiricism. Empiricism, in its strict sense, demands that the empirical content of knowledge which we claim to posses be increased to its possible maximum. Thus, the proliferation of alternatives of a view is proper to empiricism. If this is the case, the so-called consistency condition, which aims majorly to strike off alternatives, becomes therefore opposed to empiricism. For this reason, Feyerabend even criticizes the empiricists who defend the consistency condition against the proliferation of theories because their dogmatic stance portrays them as people who are subtly turning their backs on their own theory.

\subsection{Rationality in Science}

On this point, Feyerabend (1993) raises two relevant questions: 1) Is it desirable to live in accordance with the rules of a critical rationalism? 2) Is it possible to have both a science as we know it and these rules?

To the first question, Feyerabend responds that such a procedure would do us no good at all if we consider human interests and, above all, the issue of human freedom. This is because Feyerabend (1993) believes that an objective approach which does not consider personal interests or connections between the entities examined will endanger people and even turn them into miserable, unfriendly, self-righteous mechanisms without charm and humour. Hence, a reform of the sciences that makes them more anarchistic and more subjective (in Kierkegaard's choice of language) is pertinent.

Then, to the second question above, Feyerabend has a negative response. This is because Feyerabend believes that the actual development of institutions, ideas practices, and so on, often does not start from a problem but rather from some extraneous activity, such as playing, which later on can metamorphose into solutions to unrealized problems (Feyerabend, 1993).

The two answers above show us that reason, at least in the form in which it is 
being defended by logicians, philosophers, and some scientists, is not the best for science. Hence, a radical choice needs to be made: one either keeps science or retains [strict] reason, but one cannot keep both. After all, a strict principle of falsificationism or a "naïve falsification" as Lakatos calls it, would wipe out science as we know it and would even never have permitted it to be in the first place (Lakatos, 1970).

Thus, all the above taken into consideration, we could see that the principles of critical rationalism (initiated by Karl Popper) which take falsifications very seriously, increase content, avoid ad hoc (or alternative) hypotheses, and so on, as well as the principles of logical empiricism which take precision seriously, base theories on measurements, avoid unclear and falsifiable ideas, and so on, though practised in special areas, all give inadequate account of the past development of science as a whole and are liable to endanger it in the future. They give improper account of science because science is much more irrational than its strict methodological proponents try to portray and also they could endanger its progress in the future because the endeavour to make science more rational and more strictly methodic is doomed to be catastrophic on science itself. The distinctions between "science" and the so-called methods (or even "laws of reason") shows the defeat of the latter in history. The so-called "deviations", "errors", and "irrationality" could be seen as preconditions of progress. They permit knowledge to survive in our complex and difficult world, allowing us much more freedom in the scheme of things. Thus, Feyerabend asserts:

Without "chaos", no knowledge. Without a frequent dismissal of reason, no progress. Ideas which today form the very basis of science exist only because these things opposed reason: and because they were permitted to have their way (Feyerabend, 1993).

Therefore, Feyerabend (1993) concludes that even within science, reason cannot and should not be allowed to be comprehensive and that it must often be overruled, or eliminated, in favour of other agencies-for instance, how Galileo abandoned his telescopic arguments and resorted to the use of propaganda (psychological and sophist's tricks) in order to win support for Copernicanism. After all, there is not a single theory that remains valid under all circumstances and not a single agency to which appeal can always be made. Even Lakatos' ingenious methodology does not escape this indictment. Lakatos seems "liberal" because he forbids very little and he seems "rational" because he still forbids something.

From the foregoing, we have seen how Feyerabend defends his theory of scientific anarchism by going down memory lane of the development of science and, then, from the facts, he deduces that science has benefitted more from the deviations from set rules than from their obedience. Subsequently, we shall see how such anarchic approach to science (and knowledge in general) could be beneficial to Nigeria in her quest for genuine scientific development. 


\section{Application of Feyerabend's Scientific Anarchism to Proper Scientific Development in Nigeria}

The place of China, North Korea, Japan, etc., has shown that scientific theories and technological development are human creations and therefore should not be a monopoly of the West. This calls for the plurality of rationality as they are relative to their circumstances and conditions. This, as stated above, is what Feyerabend calls "epistemological anarchism." The implication of this is that there is a call for indigenous science and technology, developed by a people to control their environment, harness resources and produce goods and services, and has as its goal the improvement of the quality of human life. An example is the revival of traditional medicine in Communist China. When the Communists in the fifties forced hospitals and medical schools to teach the ideas and the methods contained in the Yellow Emperor's Textbook of Internal Medicine and to use them in the treatment of patients, many Western experts (among them Eccles, one of the "Popperian Knights") were aghast and predicted the downfall of Chinese medicine. What happened was the exact opposite. Acupuncture, moxibustion, pulse diagnosis have led to new insights, new methods of treatment, new problems both for the Western and for the Chinese physician. This is in consonance with the fact that, according to Feyerabend (1993), “... ancient doctrines and 'primitive' myths appear strange and nonsensical only because the information they contain is either not known, or is distorted by philologists or anthropologists unfamiliar with the simplest physical, medical or astronomical knowledge."

It must be pointed out that science and technology do not operate on the same level all over the world. The conception and relevance of the philosophy of indigenous science and technology is seen relative to the solution of practical and cultural needs of the people applying them. Like China, our technological development should be re-oriented towards the social and cultural context of the people.

In line with Feyerabend's view, every theory has a particular condition under which terms can be considered valid or true. This can be confirmed by the provocation of the question thrown to former Nigerian president, Olusegun Obasanjo in a TV chat of September 2001. He was asked why his administration's policies were much praised and adjudged well in the western world while in his country itself, it is hardly felt so? This points to the fact that so far, Nigeria has continued to apply western prescriptions for their scientific and technological development with very little, or even no positive result from them.

Thus, Feyerabend's scientific anarchism could be adopted as a clarion call on Nigeria to come up with scientific and technological models to actualize our own needs and aspiration. This is because the issue of technology is one relating to the most natural inclination of man to master his environment. If man's survival depends on his ability to adapt to his environment either by virtue of his natural endowment or by virtue of his innovative ingenuity, then, why should the West 
dictate what model of scientific development to adopt? Kanu (2010) asks: "since it is not in nature of man to remain forever a child of nature, would Africa not have evolved a good indigenous technology without the directive of the West?" Further, he continues:

If technology is the expression of man's self-liberation as it pertains to his relationship to nature, then, Africa should be allowed the autonomy and freedom in proportion to her ability to define accurately and harmonize her creativity, exploitative and explorative potentialities with her true needs. Given that culture provides man with a "form of life" through and in which his individual existence takes shape, and in the context of which his personal destiny can be built up, it becomes urgently necessary to shun any western model or prescription that cannot be adapted in our cultural system of environment (Kanu, 2010).

This essay, therefore, proposes the institutionalization of Nigeria's science and technology away from every disguised form of neo-colonialism which could foil the possibility of successful scientific and technological progress that is in line with the organic and historical needs of Nigerian society. In line with Feyerabend's "anything goes" methodology, any method, procedure or insight that better explains or solves the problem under investigation should be taken as more acceptable. In consonance with Feyerabend, Mukherjee opines:

Hence, in the present state of knowledge in theory and action, we cannot speak of "one", or "the only role" of value in scientific and technological development. It has to be a matter of diagnosis in a place-time-object bound field in which there is diversity of possible value significance (Mukherjee, 1977).

Corroborating the above views, Inyang-Abia (1996) is of the opinion that the basic principles of appropriate (indigenous) technology encourages diversity and selectivity which are adequately responsive to varying local resources, conditions and priorities. He goes on to explain that appropriate technology demands that the scale and complexity of technology be matched with the level, desires, needs, resources, and economic value of the people.

To cite some instances of such anarchical approach to scientific development in recent history, we go back to China once more. In the area of agro-technology, China was able to move very fast using local inputs. It was a big surprise to a Canadian diplomat to find in Cummune in the Pearl River Delta the use of wooden machine to lift water from the river for the cultivation of rice. He observed that the same simple but ingenious device was constructed by the co-operation of peasants and/or few engineers from a university. This machine also generates power for small factories and electricity for household use (Tsurumi, 1977).

Now, coming to Nigeria which is the focus of this essay, unlike the Chinese, our scientific and technological development is so aligned to the western model 
(imitation model) whereby scientific breakthroughs are expected from (and even only from) experts in the universities, government, and big business laboratories. But the Chinese successful model has no discrimination. It recognizes and encourages the potentialities, ingenuity and participation of all its citizens. It is this that made the Chinese scientific breakthrough pervasively successful. This is a lesson to Nigeria. We should ask some pertinent questions here: do we need imported, gigantic industries of the West like the Ajaokuta iron and steel industries and Kaduna oil refinery to succeed? Is it not a surprise that Nigeria can hardly boast of sufficient technological ingenuity in the comity of nations? Why has Nigeria abandoned the quest for scientific-technological self-reliance? The short-lived Biafra was able, through the activities of her local engineers, to develop certain modern technology that were expedient and responsive to the needs and challenges of a war period. Umuahia war museum is a justifying proof of this.

More instances abound where Nigeria could actually improve ingeniously in science and technology by breaking free from already set standards of scientific procedures according to the West and, rather, look inward and try to develop more indigenously (or anarchically, if we should go by Feyerabend's terminology). First, we talk of our traditional medicines which in many occasions have proven more effective than the so-called orthodox ones. For instance, it is a well-known case in the country that some diseases, like strange elephantiasis, which often prove stubborn to orthodox treatments, have often been cured by our traditional doctors or herbalists. Regrettably, despite all the breakthroughs of the traditional medicines in areas which have otherwise proven so obstinate to orthodox medicines, there is still much skepticism about its use in our contemporary era. According to Feyerabend, this scepticism is as a result of wrong approach towards the so-called tests of the traditional medicines. He writes:

In the case of herbal medicine, the approach consists of two steps. First, the herbal concoction is analysed into its chemical constituents. Then, the specific effects of each constituent are determined and the total effect on a particular organ explained on their basis. This neglects the possibility that the herb, taken in its entirety, changes the state of the whole organism and that it is this new state of the whole organism rather than a specific part of the herbal concoction, a "magic bullet", as it were, that cures the diseased organ (Feyerabend, 1993).

It is my conviction that Nigeria could become so economically buoyant from her traditional medicines if they are well developed just like India and China are today-a case whereby when one gets severely ill and they are yet to be taken to India or China for treatment, then they are yet to get to the final bus stop. And if unfortunately, they are taken there and returned with the ailment still persistent, then, the patients often resign to the will of God believing their final hour to be so near at hand.

In a similar vein, I often ask: why can Nigeria not maximize her tropicality to 
achieve the best solar energy-powered technology in the world? This would help so much in reducing our incontrollable wastes from fossil fuel and the worrisome corruption and bureaucracy in our oil industry. Besides, indigenous technologies, if well developed by us, would be seen to even be less capital intensive and yet create more job opportunities at same time as they would give rise to diversification and enhancement of individual creativities.

\section{Concluding Remarks}

\subsection{Evaluation}

Feyerabend saw himself as having undermined the arguments for science's privileged position within culture. Thus, much of his work is a critique of the position of science within Western societies. Because there is no scientific method, we cannot justify science as the best way of acquiring knowledge. More still, the results of science do not prove its excellence, since these results have often depended on the presence of "non-scientific" elements. "Science is neither a single tradition, nor the best tradition there is, except for people who have become accustomed to its presence, its benefits and its disadvantages" (Feyerabend, 1993).

It also follows that "non-scientific" procedures cannot be pushed aside by argument. To say: "the procedure you used is non-scientific, therefore, we cannot trust your results and cannot give you money for research", assumes, first, that the so-called "science" is always successful and, second, that it is successful because it uses uniform procedures. The first part of the assertion ("science is always successful") is not true, for if by "science" we mean things done by scientists-there are lots of failures too. The second part-that successes are due to uniform procedures-is not also true because there are no such procedures. Scientists are like architects who erect buildings of different sizes and different shapes and who can be judged only after the event, that is, only after they have finished their structure. It may stand up, it may fall down-nobody knows.

So far, we have seen that following Feyerabend's philosophy of proliferation of methods as against consistency conditions, we meet with the need to search for alternatives for developmental model. That is, we raise some basic questions about the intellectual framework for future scientific developmental priorities and possibilities in Nigeria, such as: are the only options of development really western model? Are there other culturally conditioned alternatives that permit people to enjoy a simpler, more satisfying life that encourage their creative energy and also that are non-exploitative, more egalitarian, more participatory and truly democratic? Are there other paths to the satisfaction of the felt needs of the people other than through the initiative development pathways of the West? Will indigenous development of science and technology strengthen the economic independence of Africa (Nigeria in particular)?

In answer to these questions, we have from all our discourse so far realized that there is no universal way to development. Development is dependent on the 
circumstances and conditions of the environment. Hence, like China and North Korea, our scientific and technological development would be our greatest source of strength, and a challenge to the imperialistic capitalist West and their so-called globalization model.

\subsection{Conclusion}

In line with the stand above, this essay calls on Nigeria to try scientific breakthroughs which must not come from experts in the universities, government, and big business laboratories. Our scientific model should be more encompassing, and more socialistic, touching every angle or sector of the national being. It should encourage the potentialities, ingenuities and participation of all citizens. Our traditional medicines, which in many occasions have proven their proficiency, must be encouraged and given a national pride of place. Yes, it could be improved upon but then, it must first of all be respected by our nation so that other nations can accord it same high acknowledgement. Our tropicality is a special gift from the creator to us which could be harnessed and maximized to achieve one of the best solar energy-powered technologies in the world. This would aid us in controlling fossil wastes and cancerous corruption and bureaucracy in our present oil industry. More still, the development of indigenous technologies would help to create more employment opportunities to our teeming unemployed youths, the corollary which would be a drastic reduction in the rate of crimes in the country. In the same vein, the example of the technological ingenuity and prowess of the short-lived Biafra should motivate us to go back to the quest for scientific-technological independence (at least, to a very appreciable level).

Thus, in all, Feyerabend's scientific anarchism should provoke and re-shift our attention to other alternatives especially in cultivating home-grown, problem-solving and practically oriented scientific and technological model of development. According to Kanu (2010), "this will not only be antipodal to the Western imperialist and their exploitative models (in the name of globalization), but will promote efficiency in the actualization of our potential resources into developmental agents and, consequently, raise Nigeria to greatness and self-sufficiency."

It should be seen that the direct impact of science and technology on culture may be that of restructuring effect but not that of destruction of that culture. Science (and technology) being social enterprise, it does not make sense outside the cultural context. That is to say, African countries should not adopt any prescription that will bring frustration to development. African (Nigerian) cultural systems possess the traits for unity with modern scientific technology. History has shown that no culture is bereft of the capacity to develop science and technology even though some people may be faster than others as a result of certain peculiar circumstances and needs. This is so because, everywhere, science does already exist in one form or another although not as structured, systematized and articulated as modern science. 
As every culture needs development in order to survive and as man's task today is to transform the world to his betterment, the Nigerian leadership should channel scientific and technological development to suit the country's socio-political demands and not irrationally falling into the gutter of Western exploitative prescriptions. Even leadership should be careful within the acclaimed "kindness of transferred technology". So far, the system of technological transfer in Nigeria up to the present day has made its aim of development a mirage, and this is predicated on the covert Western quest for monopoly of development and the subjection of African countries to dependency. Leadership should create room for appropriate indigenous technology that is in consonance with the environment and the culture of the people. The social and political atmosphere should aid the entrenchment of indigenous technology into our cultural system. African cultural values are humanistic and communalistic. Being communalistic, life is essentially social. The natural tendency to development will be marriage of this culture with socialism, since African traditional system has affinity to that (Kanu, 2010).

\section{Conflicts of Interest}

The authors declare no conflicts of interest regarding the publication of this paper.

\section{References}

Bacon, F. (1952). Novum Organum, Aphorism 50. Britannica Great Books, 30. Chicago: Encyclopedia Britannica, Inc.

Butterfield, H. (1965). The Whig Interpretation of History. New York: Oxford University Press.

Feyerabend, P. (1993). Against Method(3rd ed.). London and New York: Verso.

Inyang-Abia, M. E. (1996). Technology: Transfer or Appropriate. In P. Alozie (Ed.), Technology, Science and Environment: A Current Overview. Aba: All Industries.

Kanu, M. A. (2010). Globalization as a Constraint to Genuine Development of Science and Technology in Africa: Feyerabendian Philosophy as an In-Road to Genuine Development in Africa. In The Humanities and Globalization in the Third Millennium. Faculty of Arts, NAU, Awka: Rex Charles and Patrick Ltd.

Lakatos, I. (1970). Falsification and the Methodology of Scientific Research Programmes. In I. Lakatos, \& Musgrave (Eds.), Criticism and the Growth of Knowledge. Cambridge: Cambridge Press.

Lenin, V. I. (1967). Left-Wing Communism-An Infantile Disorder. Selected Works, 3. London: London Press.

Marx, K. (1918). Introduction to the Critique of Political Economy. Chicago: Chicago Press.

Mukherjee, R. (1977). Some Introductory Remarks. In Scientific-Technological Revolution: Social Aspects. London: SAGE Publications.

Munevar, G. (2000). A Rehabilitation of Paul Feyerabend. In J. Preston (Ed.), The Worst Enemy of Science? Essays in Memory of Paul Feyerabend. New York: Oxford University Press. 
Tsurumi, K. (1977). Some Potential Contributions of Latecomers to Technological and Scientific Revolution: A Comparison between Japan and China. In Scientific-Technological Revolution: Social Aspects. London: SAGE Publications. 